Dr. Atilla AYDIN - Zümrüt MÜFTÜoĞLU / Ulusal Yapay Zekâ Stratejisi ile Ülkemiz Yeni Bir Atılım Başlatmıştır

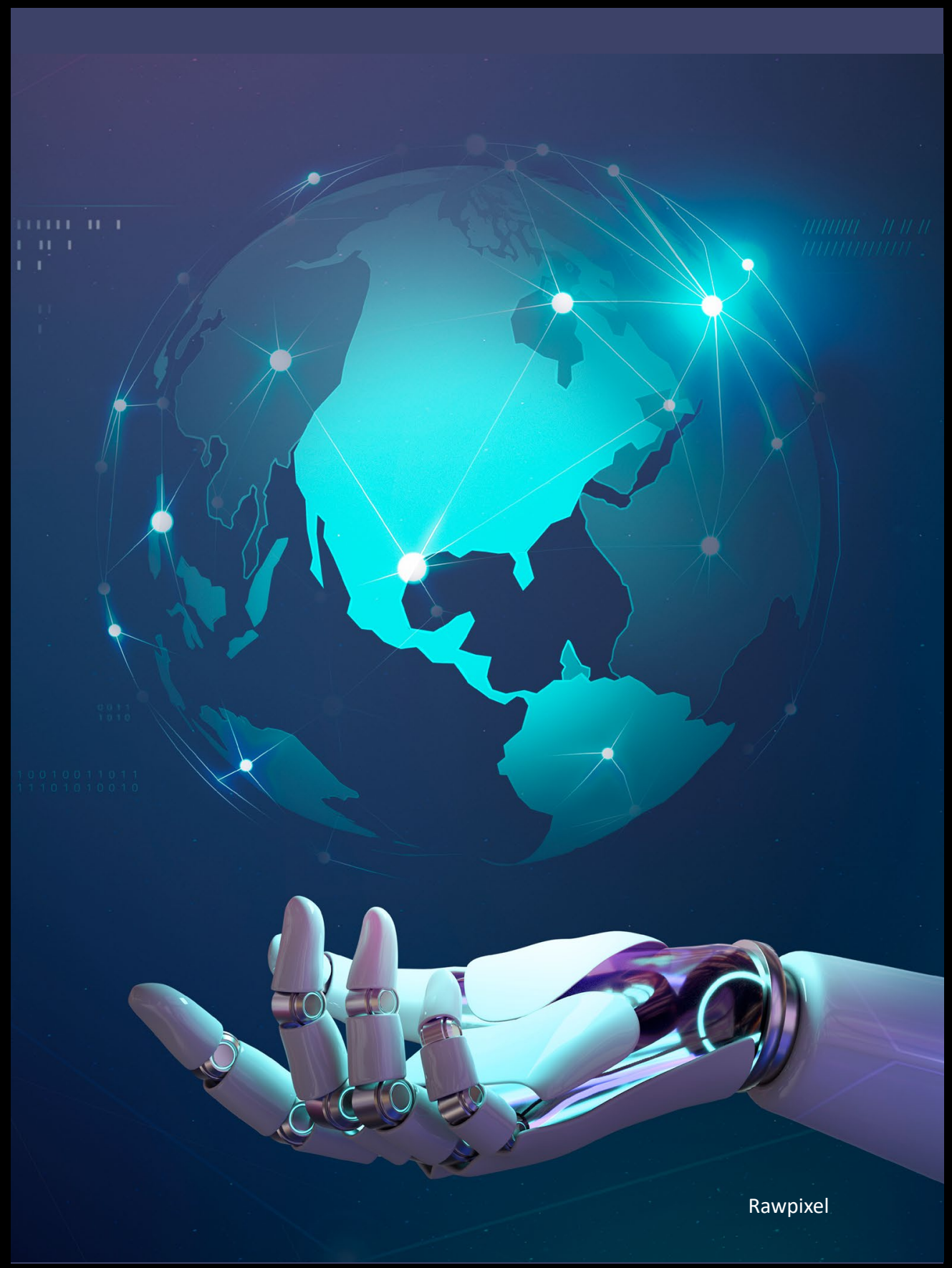




\section{Ulusal Yapay Zekâ Stratejisi ile Ülkemiz Yeni Bir Atılım Başlatmıştır}

\section{Dr. Atilla AYDIN* Zümrüt MÜFTÜOĞLU*}

Büyük hacimli dijital veri kümelerini işleyen algoritmaların günlük yaşamımız üzerinde giderek daha belirleyici ve yönlendirici bir hâl aldığını görüyoruz. 1990'lı yıllardan itibaren internetin iş yapma şeklimizi tamamen değiştirdiği gibi kullanmakta olduğumuz arama motorlarından sesli asistanlara, finansal analizden sağlık karar destek sistemlerine ve yeni nesil araçlardaki otonom sürüş özelliklerine kadar hayatımızın tüm alanlarından bu değişime örnekler vermek mümkündür. Bu akıllı algoritmaların temelinde yatan yapay zekâ (YZ) teknolojilerinin uygulama alanı giderek artmaktadır. Alışkanlıklarımızı ve iş yapış şekillerini dönüştürme potansiyeline sahip olan YZ'nin yeni bir teknolojik kalkınma çağını başlattığı ifade edilmekte ve küresel ekonomik yapı üzerinde İnternet devriminden daha büyük bir etki yaratması beklenmektedir. YZ destekli sistemlerin köklü dönüşümlerin arifesindeki toplumsal, ekonomik ve uluslararası düzende işleyişin kurallarını baştan yazarak yeni firsatlar ve riskler ortaya çıkaracağı değerlendirilmektedir.

Tarihsel süreç açısından bakıldığında, dijital teknolojilerin küreselleşmeyi yeni bir boyuta taşıyıp hızlandırdığı net olarak gözlemlenmektedir. Geçtiğimiz yüzyılın güç dengeleri çerçevesinde şekillenip olgunlaşan küresel değer zincirleri, dijital teknolojilerin mümkün kıldığı daha üretken iş süreçleri doğrultusunda yeniden şekillenmektedir. Bu teknolojilerin arasından son yıllarda ön plana çıkan YZ teknolojileri, mevcut sistemlerin kolektif ve adaptif bilişim kabiliyetlerini üst seviyeye çıkararak dijital dönüşüme yeni bir ivme kazandırmıştır. Doğal olarak bu değer zincirlerinin etkin şekilde işlemesini sağlayan uluslararası kural ve normlar da yeni dinamikler doğrultusunda yeniden kurgulanacaktır. Bunun yanında; kovid-19 pandemisi, iklim değişikliği, finans krizleri ve göç hareketleri gibi küresel sorunlar veriye dayalı olan küresel çözüm arayışlarını gündeme getirmiştir. Türkiye de dâhil birçok ülke- 
nin politika gündeminde yoğun şekilde yer alan mahremiyet, dijital platformların vergilendirilmesi, kimlik yönetimi, siber güvenlik ve sınır aşan veri transferleri gibi tartş̧malar aslında küresel ekonomide yaşanan yapısal dönüşüm sürecinin doğal sonucudur.

Cumhurbaşkanlığı Dijital Dönüşüm Ofisi Başkanlığının kuruluş amaçları dikkate alındığında; Cumhurbaşkanlığı Hükûmet Sistemi'nin getirdiği daha çevik bir yönetim anlayışıyla birlikte bilgi toplumu, dijital ekonomi ve siber vatan kavramlarına verilen önem ortaya konulmaktadır. Diğer taraftan, YZ alanının dijital devlet, akıllı şehirler, geniş bant altyapısı, ulaşım, imalat sanayisi, yazılım sektörü, eğitim ve istihdam gibi birçok alandaki politika ve stratejileri de etkilemesi söz konusudur. Dijital dönüşüm çalışmaları sürecinde, ülkemizde $Y Z$ alanında yeni bir atılım yapmanın gerekliliği görülmüş ve bu bakış açısıyla, Türkiye $Y Z$ stratejisini yayımlayan ülkeler arasında yerini almıştır. Cumhurbaşkanlığı Dijital Dönüşüm Ofisi Başkanlığı ile Sanayi ve Teknoloji Bakanlığı iş birliğinde, ilgili tüm paydaşların etkin katılımıyla hazırlanan "Ulusal Yapay Zekâ Stratejisi (UYZS) 2021-2025"e ilişkin Cumhurbaşkanlığı Genelgesi, 20 Ağustos 2021 tarihinde Resmî Gazete'de yayımlanarak yürürlüğe girmiştir.'

Lansmanı 24 Ağustos 2021 tarihinde Gebze Bilişim Vadisi'nde gerçekleştirilen Strateji, YZ teknolojilerinin beslediği bu küresel dönüşüme ülkemizin insanlık adına katkı verebilmesi için önemli bir firsattrr. Stratejimiz, ülkemizin bu süreçten mümkün olduğunca faydalanmasını sağlamak amacıyla ilgili tüm paydaşların katkılarının da alındığı kapsamlı bir çalışmanın ürünüdür. Ayrıca katılımcı bir süreç yürütmek amacıyla hazırıı çalışmaları kapsamında Ankara ve Gebze'de tüm paydaşların yer aldığı çalıştaylar ile firmaların YZ çalışmaları hakkında bilgi edinilmek üzere anket düzenlenmiştir. Bu çerçevede, ekonomik ve sosyal yaşamda $\mathrm{YZ}$ ile ortaya çıkan paradigma değişiminin şekillendirdiği küresel eğilimler ve ülkemizin mevcut durumu incelenmiştir. Dünyadaki ve ülkemizdeki durumu kısaca aşağıdaki şekilde özetlemek mümkündür²:

- YZ'nin sosyoekonomik getirileri, dünyadaki birçok ülkeyi kapsayan küresel bir yarışın başlamasına neden olmuştur. Küresel YZ harcamalarının 2020 yılında yaklaşık 50,1 milyar ABD doları olduğu tahmin edilmektedir. Pazar büyüklüğünün 2024 yılına kadar \%20,1'lik yıllık büyüme oranıyla 110 milyar ABD dolarını aşması beklenmektedir. Birçok araştırmaya göre YZ alanının, 2030 yılına kadar küresel ekonomiye 13-15,7 trilyon ABD doları katkı yaparak \%13-14 arasında büyüme sağlayacağı öngörülmektedir.

${ }^{1}$ Ulusal Yapay Zekâ Stratejisi (2021-2025), T.C. Resmî Gazete, (31574, 20 Ağustos 2021), https://www.resmigazete.gov.tr/ eskiler/2021/08/20210820-22.pdf.

${ }^{2}$ Ulusal Yapay Zekâ Stratejisi 2021-2025, Ağustos 2021, https://cbddo.gov.tr/uyzs. 
- Dünya genelinde, YZ alanında toplam istihdamın 2019 yılı itibarıyla 250.000 kişiye yaklaşth̆̆ değerlendirilmektedir. Gelişmekte olan meslek kümeleri arasında görülen "Veri ve $Y Z$ " alanında istihdam artışının diğer kümelere göre daha yüksek olması beklenmektedir. YZ alanında ortaya çıkan ihtiyaçlar doğrultusunda hukuk, sosyoloji, etik, ekonomi gibi farklı disiplinlerde de uzmanlıkların geliştiği görülmektedir. YZ alanındaki istihdamın büyüklüğü ve niteliği açısından mevcut olan bu belirsizlik sadece ülkemize has bir durum olmayıp bu alanda daha sağlıklı veri oluşturmaya yönelik çalışmalar uluslararası düzeyde devam etmektedir.

- ABD ve Çin'de YZ odaklı girişim sayısı 2.000 adeti bulurken ülkemizde yerleşik YZ girişimi sayısı 200 adet civarındadır. Girişimlerin yaklaşık \%50'si teknoparklarda iken \%73'ü İstanbul'da bulunmaktadır. Girişim sermayesi fonlarının YZ alanına ilgisinin küresel ekonomik durgunluğa rağmen yüksek düzeyde olduğu ifade edilmektedir.

- Akademik başarı anlamında da ABD, Çin ve Avrupa bölgesinin önde olduğu görülmekte olup ülkemizin bu alanda kayda değer başarıları söz konusudur. Alanda çalışmalar yürüten 1.218 akademisyen mevcuttur. 2009-2018 yılları arasında YZ alanındaki Türkiye menşeli uluslararası endeksli yayın sayısına göre ülkemiz dünya sıralamasında 16'ncı sıradadır. Diğer taraftan, YZ ve ilgili teknolojileri kapsayan alanlarda atff etkisinde dünya ortalaması 5,37 iken Türkiye ortalaması 6,21 düzeyindedir.

- Üniversitelerimiz, dijital dönüşümün dönüştürücü etkilerine güncelledikleri eğitim programları ile uyum sağlamaya çalışmaktadırlar. Bu bağlamda, ilki 2018 yılında olmak üzere 4 üniversitemizde $Y Z$ alanında lisans programı açılmıştır. Ayrıca, alanda ihtisaslaşmayı sağlamak üzere $Y Z$ özelinde 14 yüksek lisans ve 1 doktora programı ile büyük veri, robotik ve akıllı sistemlere yönelik 24 yüksek lisans ve 5 doktora programı açılmıştır. İlgili alanlarda araştırma merkezlerinin sayısı da giderek artmaktadır. Hâlihazırda YZ odaklı 13; büyük veri, robotik ve akıllı sistemlere yönelik 20 merkez kurulmuştur.

- Ülkemizde YZ projelerine destek giderek artmaktadır. TÜBITAK, son 10 yıl içerisinde yürüttüğü yaklaşık 1.715 Ar-Ge ve yenilik projesine 1,7 milyar TL (2020 yılına ait fiyatlar ile) finansman sağlamıştır. Bu finansmanın yaklaşık \%25'i akademiye verilen destekler iken, \%75'e yakını sanayinin gelişimine yönelik özel sektöre verilen Ar-Ge destekleridir.

- Ülkemizde kamu kurumlarının yeni nesil teknolojilere hazır hâle getirilmesi ve veriye dayalı etkin karar alma süreçlerine sahip olabilmeleri için pilot uygulamalara başlanmıştır. Bakanlıklar tarafindan yürütülen; "Daha Zeki UYAP”, "iş Sağlı̆̆ı ve Güvenliği Bilgi Yönetim Sistemi”, anayurt güvenliği, e-Triyaj; yangın ve süneyle 
mücadele ve Kolay İhracat Platformu gibi önemli projeler söz konusudur. Cumhurbaşkanlığı Dijital Dönüşüm Ofisi Başkanlığı ile Gazi Üniversitesinin ortak çalışması sonucunda hayata geçirdiği Türk Beyin Projesi kapsamında YZ teknolojileri kullanılarak MR görüntülerinden çeşitli anomalilerin tespit ve teşhisini kolaylaştıracak, acil vakaların tedavisini hızlı bir şekilde başlatmaya ve çeşitli komplikasyonların oluşma intimalini azaltmaya imkân verecek bir karar destek sistemi geliştirilmektedir.

- YZ kullanımının giderek yaygınlaşt̆ğı bir diğer önemli alan olan endüstriyel ve hizmet robotu kullanımı ülkemizde giderek yaygınlaşmaktadır. Ülkemizde özel sektör kuruluşlarının endüstriyel ve hizmet robotu kullanım oranı \%5,1 olup büyük ölçekli işletmelerde bu oran \%19,6'ya yükselmektedir. Uluslararası Robotik Federasyonuna göre ise imalat sektörünün genelinde 10 bin çalışan başına yaklaşık 40 robot düşerken otomotiv sektöründe 200 robot düşmektedir.

Ülkemizin ilk ulusal YZ stratejisi olma özelliğini taşıyan UYZS, On Birinci Kalkınma Planı ile 2021 Yılı Cumhurbaşkanlığı Yıllık Programları doğrultusunda Türkiye'nin önümüzdeki beş yıl içinde bu alanda yürüteceği çalışmalar için ana yol haritasını teşkil edecektir. Strateji, “Dijital Türkiye” vizyonu ve "Millî Teknoloji Hamlesi” doğrultusunda kalkınma hedeflerimize hizmet eden en önemli taşıyıcılardan biridir.

UYZS'nin vizyonu, “müreffeh bir Türkiye için çevik ve sürdürülebilir yapay zekâ ekosistemiyle küresel ölçekte değer üretmek" olarak belirlenmiştir. Strateji, bu vizyonu hayata geçirmek üzere ulusal politika ve ihtiyaçlar doğrultusunda ve uluslararası kuruluşların YZ strateji önerilerini dikkate alarak 6 stratejik öncelik etrafinda tasarlanmıştır:

1. YZ Uzmanlarını Yetiştirmek ve Alanda İstihdamı Artırmak

2. Araştırma, Girişimcilik ve Yenilikçiliği Desteklemek

3. Kaliteli Veriye ve Teknik Altyapıya Erişim İmkânlarını Genişletmek

4. Sosyoekonomik Uyumu Hızlandıracak Düzenlemeleri Yapmak

5. Uluslararası İş Birliklerini Güçlendirmek

6. Yapısal ve İş Gücü Dönüşümünü Hızlandırmak

Bu stratejik öncelikler kapsamında 24 amaç ve 119 tedbir belirlenmiştir. Amaçlar; birey, firma ve kamu kurumları özelinde farkındalık sağlama ile başlayan ve deneme, uygulama, yönetme ve nihayetinde yapısal dönüşümü hayata geçirme şeklinde ilerleyen bir olgunlaşma rotasının takip edilmesine imkân verecek tedbirleri tanımlamaktadır. Uygulayıc kurumlar, bu amaç ve tedbirler doğrultusunda eylemlerini belirleyecekler ve hayata geçireceklerdir. 
UYZS, hâlihazırda küresel ölçekte yaşanmakta olan ve YZ gibi yeni nesil dijital teknolojilerin beslediği bu dönüşüme, $Y Z$ 'nin potansiyel fayda ve risklerini gözeterek, ülkemizin insanlık adına katkı verebilmesini ve bu süreçten mümkün olduğunca faydalanmasını amaçlamaktadır. Strateji, ülkemizin YZ odaklı yeni bir dijital kalkınma atılımı yapması için oluşturulmuştur. UYZS kapsamında belirlenen hedefler ile 2025 yılı sonunda YZ'nin GSYH'ya katkısının \%5'e yükseltilmesi, alanda istihdamın 50.000 kişiye çıkarılması, lisansüstü düzeyde mezun sayısının 10.000 'e yükseltilmesi, yerli YZ uygulamaların ticarileştirilmesinin desteklenerek ülkemizin sıralamalarda ilk 20 ülke içerisinde yer alması amaçlanmaktadır.

Strateji, dünya genelinde yaygın olarak kabul gören "güvenilir ve sorumlu YZ" ilkeleri doğrultusunda şekillendirilmiştir. AB, OECD ve UNESCO tarafindan son yıllarda kabul gören etik değerler ve düzenlemelere güçlü referanslar verilmiş ve uluslararası toplum ile uyumlu bir yaklaşım benimsenmiştir. Bu minvalde, YZ uygulamalarının etik ve hukuki boyutlarını ele alan faaliyetlerin yürütülmesi ve uluslararası arenada bu alanda yürütülen çalışmalara aktif olarak katılım sağlanması hedeflenmiştir.

UYZS'nin odağında "beceri”, "veri” ve "altyapı" olarak belirlenen üç temel YZ yetkinliği yer almaktadır. Temel yetkinliklerin, ekosistem paydaşlarının dâhil olacağı bir yönetişim ve stratejik uyum süreci ile geliştirilmesi hedeflenmektedir.

Bu kapsamda;

- YZ alanında istihdamın niteliğinin ve niceliğinin artırılmasına yönelik beceri haritalarının çıkarılması, mesleki tanımların yapılması, eğitim içeriklerinin zenginleştirilmesi ve çalışma koşullarının iyileştirilmesi gibi faaliyetler özel sektör, ilgili STK'ler ve üniversitelerle birlikte yürütülecektir.

- Cumhurbaşkanlığı Dijital Dönüşüm Ofisi Başkanlığı Büyük Veri ve Yapay Zekâ Uygulamaları Dairesi Başkanlığı koordinasyonunda "Kamu YZ Ekosistemi” kurulacaktır. Bu yapı, bakanlıklar başta olmak üzere merkezi ve yerel yönetim kurum ve kuruluşlarının YZ ve ileri analitik projeleri için daha hızlı yol almalarına imkân tanıyacaktır.

- Sanayi ve Teknoloji Bakanlığı Millî Teknoloji Genel Müdürlüğü koordinasyonunda TÜBITAK Yapay Zekâ Enstitüsü bünyesinde "Sektörel Birlikte Geliştirme Laboratuvarları" kurulacaktır. İhtiyaçlar doğrultusunda genişletilecek olan bu laboratuvarlarda, çok paydaşlı sektörel YZ uygulamalarının geliştirilebilmesi ve test edilebilmesi için kurumlar kendilerine özel sağlanacak altyapı ve veri alanları ile desteklenecektir.

- Açık Devlet Verisi Portali ve Ulusal Veri Sözlüğü çalışmaları sayesinde kamu kurumlarının veri kalitesi artırılacak ve anonimleştirilmiş veri setlerinin üretilerek paylaşımı hızlandırılacaktır. Kamu kurumları arasında güvenli veri yönetişimini sağlamak üzere 
"Kamu Veri Alanı" kurulacaktır. Bu verilerden daha fazla değer üretmek için kitle katılımını destekleyen ve açık kaynak ekosistemini geliştirici faaliyetler yürütülecektir.

- Kamu kurumlarının ve özel sektör kuruluşlarının yapısal ve iş gücü dönüşümü, YZ alanındaki gelişmeler doğrultusunda desteklenecektir. Yapısal dönüşümü hızlandırmak ve sağlıklı bir zemine oturtmak üzere rehberler hazırlanacaktır. Servis olarak sunulacak Kamu YZ Platformu ile uygulama öncesi hazırlık süreci ve tecrübe aktarımı kolaylaştırılacaktır. Hem kamu kurumları hem de özel sektör için problem havuzlarının oluşturulması ve kullanım senaryolarının belirlenmesi sağlanacaktır. Uygulama geliştirme ve işletim sürecinde referans modellerin kullanımını teşvik etmek üzere Güvenilir YZ Damgası yaklaşımı test edilecektir. YZ ile ortaya çıkan yeni meslekler de göz önüne alınarak sektörel iş birlikleri ile mevcut iş gücüne yönelik eğitim ve sertifikasyon programları yürütülecek, iş gücünün uyumu hızlandırılacaktır.

Stratejide yer alan ortak kabuller ve bu kapsamda hazırlanması öngörülen rehberler, yaşayan ve sürekli gelişen bir referans mahiyetindedir. Diğer ülkelerin de benzer ihtiyaçlarla strateji belgelerini süreç içerisinde güncelledikleri görülmektedir. Türkiye'nin sosyoekonomik yapısını YZ alanındaki hızı ı gelişmelere uyumlaştırmak için bir taraftan büyük hatalar yapmayacak kadar ihtiyatlı, diğer taraftan da firsatlardan istifade edebilecek ölçüde hızlı hareket edilmesi gereklidir. Böylesi belirsizliklerin olduğu YZ alanındaki ulusal stratejinin; deneyen, keşfeden, öğrenen ve bu doğrultuda kendisini sürekli olarak güncelleyen bir ekosistemin oluşturulmasına dayanması kaçınılmazdır. Bu bağlamda, UYZS keşfedici bir nitelik taşımakta olup temelde sosyoekonomik yapıda dönüşümü yönetebilecek çevik ve sürdürülebilir bir ekosistem teşkil etmeyi ve bu ekosistemin işleyişindeki olası verimsizlikleri mümkün olduğunca azaltmayı amaçlamaktadır.

UYZS kapsamındaki tedbirlerin ve hazırlanacak eylem planlarının etkin şekilde hayata geçirilebilmesi için Cumhurbaşkanlığı Dijital Dönüşüm Ofisi Başkanlığı ile Sanayi ve Teknoloji Bakanlığı koordinasyonunda yürütülecek iki katmanlı ve çevik bir yönetişim mekanizması kurgulanmıştır.

- Illk katmanda; Cumhurbaşkanı Yardımcısı başkanlığında toplanacak olan "Ulusal Yapay Zekâ Stratejisi Yönlendirme Kurulu" kapsamında üst seviye koordinasyon ve karar verme mekanizmaları yer alacaktır.

- İkinci katmanda ise UYZS uyarınca hayata geçirilecek çalışmaların etkin şekilde kurgulanıp yürütülmesine yönelik teknik ve idari mekanizmalar oluşturulacaktır. Bu kapsamda, tüm paydaşların katılımının sağlanacağı "teknik altyapı", "veri yönetişimi" "beceri, "hukuk ve etik" ile "güvenilir ve sorumlu $\mathrm{YZ}$ " konularında çalışma grupları kurulacaktır. 
Ülkeler için YZ ile gündeme gelmiş çözüm bekleyen alanlar artmaktadır. Teknolojinin nerede geliştirildiği, algoritmaları kimin yazdığı ve üretilen dijital verilerin nasıl kullanıldığı yakın dönemin en önemli tartışma sahası olacaktır. Diğer taraftan dünyada; ekonomik refah, kamu düzeni, verinin serbest dolaşımı, mahremiyet, dijital egemenlik gibi kavramlar arasına sıkışan bir kalkınma söylemi söz konusudur. Ancak, UYZS ile YZ alanındaki kalkınma paradigmasını, ekonomik refah ve kamu düzeni üzerinden şekillendirmenin ötesinde tedbirler ortaya konması oldukça kritiktir. Bir taraftan YZ teknolojilerinin sosyoekonomik yapıya nüfuzunu hızlandırırken, diğer taraftan da bu teknolojilerin özelde halkımızın ve genelde de tüm insanlığın faydasına olacak şekilde kullanılmasını sağlayacak kural ve düzenlemelerin oluşturulması planlanmıştır.

Teknolojik atılımlar çağdaş dünya jeopolitiğinin dönüşen çehresinde en belirleyici unsurlardan biri hâline gelmiştir. Ülkemizin geliştirdiği YZ destekli insansız hava araçları ulusal savunmanın ve kamu düzeninin sağlanmasında paradigma değişikliğine sebep olmaktadır. Unutulmamalıdır ki dünyada birçok teknoloji ilk önce askeri alanda gelişmiştir. Ancak YZ alanında başarının anahtarı, farklı disiplinlerde çözüm üretebilme kapasitesinde yatmaktadır. Alandaki küresel rekabetin seyri; eğitim, tarım ve sağıık gibi farklı sektörler ile malzeme teknolojileri, kuantum, siber güvenlik ve biyoteknoloji gibi farklı teknolojilerin kesişebilmesine endekslidir. Teknolojik altyapısında, beşerî sermayesinde ve iş süreçlerinde dijital dönüşümün gerektirdiği iyileştirmeleri vakitlice yapabilen ülkelerin önümüzdeki dönemin kazananları olacağı aşikârdır. Fiziksel dünya ile siber ortamın iç içe geçtiği ve çok boyutlu şekilde etkileşime girdiği bu yeni dünyanın işleyişi ve kuralları vatandaşlarımızın, özel sektörümüzün, kamu kurumlarımızın ve üniversitelerimizin tamamını köklü şekilde etkileyecektir.

Ulusal Yapay Zekâ Stratejisi ile hayata geçirilecek tedbirler sayesinde; YZ projelerinin etkin şekilde yürütülmesi, ülkemizin $Y Z$ ekosisteminin olgunluk seviyesinin yükseltilmesi ve küresel ölçekte değer üretilmesi sağlanacaktır. Tüm bu gelişmeler sağlanırken $Y Z$ sistemlerinin ortak değerlerimize uygun olarak geliştirilmesi ve hayata geçirilmesi önemlidir. Sayın Cumhurbaşkanımızın ifade ettiği üzere: “Köklü medeniyet tecrübemizle harmanlanmış yeni bir teknoekonomik atılım yaparak topyekûn insanlığa değer katma imkânımız var." Bu sayede, YZ teknolojilerinin mümkün olan en üst düzeyde yerli ve millî olarak geliştirilmesi ile ülkemizin teknolojik bağımsızIığı güçlendirilerek hem ekonomik refah hem de ulusal güvenlikte sürdürülebilirlik mümkün olacaktır. 